\title{
Growth hormone deficiency during young adulthood and the benefits of growth hormone replacement
}

\author{
M Ahmid' ${ }^{1}$ C G Perry' ${ }^{2}$ S F Ahmed ${ }^{1}$ and M G Shaikh ${ }^{1}$ \\ 'Developmental Endocrinology Research Group, Royal Hospital for Children, School of Medicine, \\ University of Glasgow, Glasgow, UK \\ ${ }^{2}$ Department of Endocrinology, Queen Elizabeth University Hospitals, Glasgow, UK
}

Correspondence

should be addressed

to M G Shaikh

Email

guftar.shaikh@nhs.net

\begin{abstract}
Until quite recently, the management of children with growth hormone deficiency (GHD) had focussed on the use of recombinant human GH (rhGH) therapy to normalise final adult height. However, research over the past two decades that has demonstrated deficits in bone health and cardiac function, as well as impaired quality of life in adults with childhood-onset GHD (CO-GHD), has questioned this practice. Some of these studies suggested that there may be short-term benefits of rhGH in certain group of adolescents with GHD during transition, although the impact of GHD and replacement during the transition period has not been adequately investigated and its long-term benefits remain unclear. GH therapy remains expensive and well-designed long-term studies are needed to determine the cost effectiveness and clinical benefit of ongoing rhGH during transition and further into adulthood. In the absence of compelling data to justify widespread continuation of rhGH into adult life, there are several questions related to its use that remain unanswered. This paper reviews the effects of growth hormone deficiency on bone health, cardiovascular function, metabolic profile and quality of life during transition and young adulthood.
\end{abstract}

\section{Key Words}

- adolescence with childhood-onset growth hormone deficiency

- transition

\section{Introduction}

Growth hormone deficiency (GHD) is an endocrine condition that can potentially impact on an individual's life from childhood, adolescence to young adulthood and beyond. In UK, the prevalence of congenital childhoodonset GHD (CO-GHD) has been estimated to be about 1 in 3500-4000 live births, whereas the prevalence of adult onset (AO-GHD) in addition to those with previous CO-GHD is also about 1 in 3000 of the UK adult population $(1,2)$. In addition to linear growth, the GH-IGF axis has important metabolic effects on a variety of target tissues
(Fig. 1). Historically, treatment with recombinant human $\mathrm{GH}$ (rhGH) was discontinued at final height as defined by a growth velocity less than $2 \mathrm{~cm} /$ year (1). However, extensive research over the past two decades that has demonstrated deficits in bone health and cardiac function, together with impaired quality of life in adults with CO-GHD after completion of childhood treatment (3, 4, $5,6)$, has questioned this practice. Although there are a number of reports of a beneficial impact on continuation of rhGH therapy beyond attainment of final height, there

http://www.endocrineconnections.org
$\begin{array}{lr}\text { DOI: } 10.1530 / E C-16-0024 & 2016 \text { The authors } \\ \end{array}$

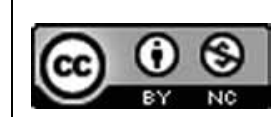

This work is licensed under a Creative Commons Attribution-NonCommercial 4.0 International License. 


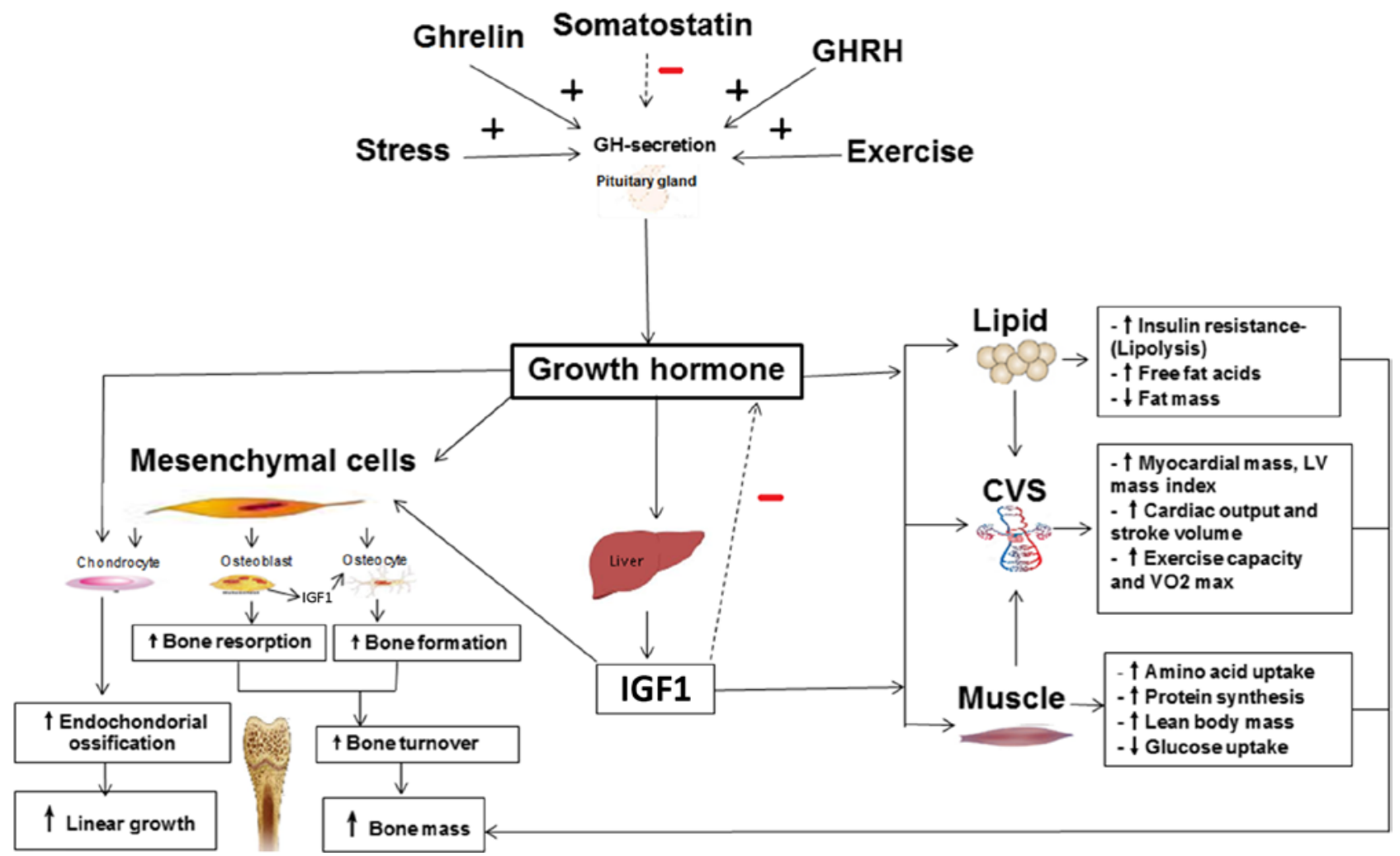

Figure 1

GH-IGF1 axis and actions in bone, muscle and body metabolism. GH secretion is regulated by three peptides: GH-releasing hormone (GHRH), ghrelinstimulating GH release and somatostatin (SS)-inhibiting GH release. In circulation, GH stimulates the liver and other peripheral tissues to produce insulin-like growth factor-1(IGF1). GH/IGF1 stimulates longitudinal growth, enhances bone mass, and regulates bone metabolism. GH promotes the positive protein balance in skeletal muscle and has lipolytic effects which may play a role in maintaining glucose homeostasis with decreased insulin sensitivity which all promote cardiovascular system (CVS) functional capacity and maximal oxygen consumption $\left(\mathrm{VO}_{2}\right.$ max).

are several studies where the results are less conclusive in determining the clinical and cost effectiveness of rhGH treatment during transition, especially with treatment costing up to $£ 5000$ per year in adulthood (7). The current guideline has approved continuation of GH replacement in those who were confirmed to have persistent GHD through the transition phase, although the evidence base underlying this recommendation is limited (8).

The primary aim of this review was to identify what evidence is available on the risks of GHD and the benefits of rhGH therapy during the transition period in the following areas: bone mass, body compositions, metabolic profiles and quality of life.

The literature search was conducted in the following databases: MEDLINE(Ovid), PubMed, Cochrane Library databases, Web of Science and Scopus in December 2015. The inclusion criteria for studies were randomised controlled clinical trials, longitudinal and case-control studies comparing discontinuation/continuation/and recommencing rhGH therapy in young adult with CO-GHD (aged between 15 and 30 years). Exclusion criteria were animal studies, studies of adults with CO-GHD, adultonset GHD, short stature and other endocrine conditions. Key outcome measures of selected studies are reported in tables and in the text. Figure 2 presents a brief summary of the literature review process and selection of studies.

\section{Consequences of rhGH cessation and replacement during transition}

\section{Bone mass and risk of fracture}

Bone mass: Cross-sectional and observational studies of bone density in rhGH-treated children with CO-GHD at time of completing linear growth have shown inconsistent findings with either low areal bone mineral density (BMD) $\left(\mathrm{g} / \mathrm{cm}^{2}\right)$, normal or slightly reduced total body (TB) BMD, bone mineral density (BMC) and lumber spinal (LS) volumetric mineral apparent density (BMAD) $\left(\mathrm{g} / \mathrm{cm}^{3}\right)$ $(9,10,11,12,13)$ (Table 1$)$. Early rhGH treatment in http://www.endocrineconnections.org DOI: 10.1530/EC-16-0024 (c) 2016 The authors Published by Bioscientifica Ltd
This work is licensed under a Creative Commons Attribution-NonCommercial 4.0 International License. 


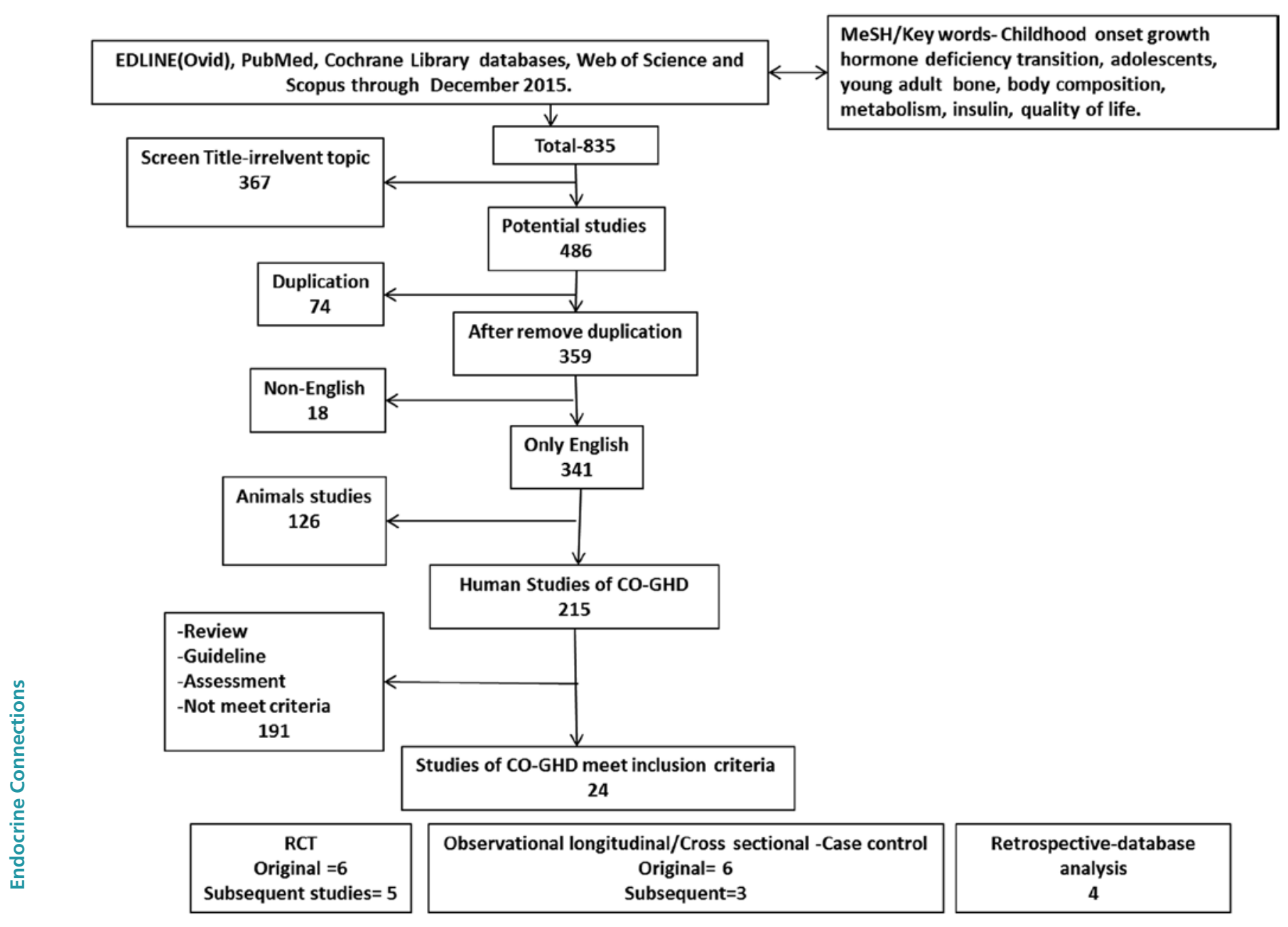

Figure 2

Flow diagram of the literature review process and selection of studies.

childhood results in better indices of bone mass on completion of treatment at final height (9). Beyond transition, a longitudinal study reported a delayed timing of peak bone mass at LS, and a rapid decline over the following 2 years was observed in adolescents with CO-GHD who discontinued rhGH after final height compared with controls (14).

Therefore, there was a concern that childhood rhGHtreated subjects with CO-GHD may not achieve peak bone mass as a consequence of discontinuing GH treatment at final height.

Over the past few decades, a series of clinical trials studies have been conducted to examine the effects of continuation, discontinuation, and recommencement of rhGH during the transition phase of adolescents with CO-GHD, but thus far, they yield conflicting results (Table 2). Continuation of rhGH is reported to be associated with an increase in TB-BMC and LS-BMD in the range $3-6 \%$ after either 1 year $(4)$ or 2 years $(15,16,17)$ as assessed with dual-energy X-ray absorptiometry (DXA). However, this net gain is similar to what would be expected in the normal population during this stage $(18,19)$. It was also reported that bone mass does continue to increase in adolescents who discontinue rhGH therapy, yet the net gain is about half of that achieved by adolescents who continue rhGH therapy $(15,16)$.

By contrast, other studies have shown no change in BMD up to 2 years following discontinuation of rhGH after attainment of final height (11) and no benefit from continuation of rhGH 2 years after final height (20, 21). It was, therefore, proposed that 2 years was a safe period to be without rhGH, after which rhGH treatment would be recommenced in confirmed GHD patients. However, according to Tritos and coworkers, an interval of

$$
\begin{array}{|lr}
\hline \text { http://www.endocrineconnections.org } & \text { ○ } 2016 \text { The authors } \\
\text { DOI: } 10.1530 / \text { EC-16-0024 } & \text { Published by Bioscientifica Ltd }
\end{array}
$$



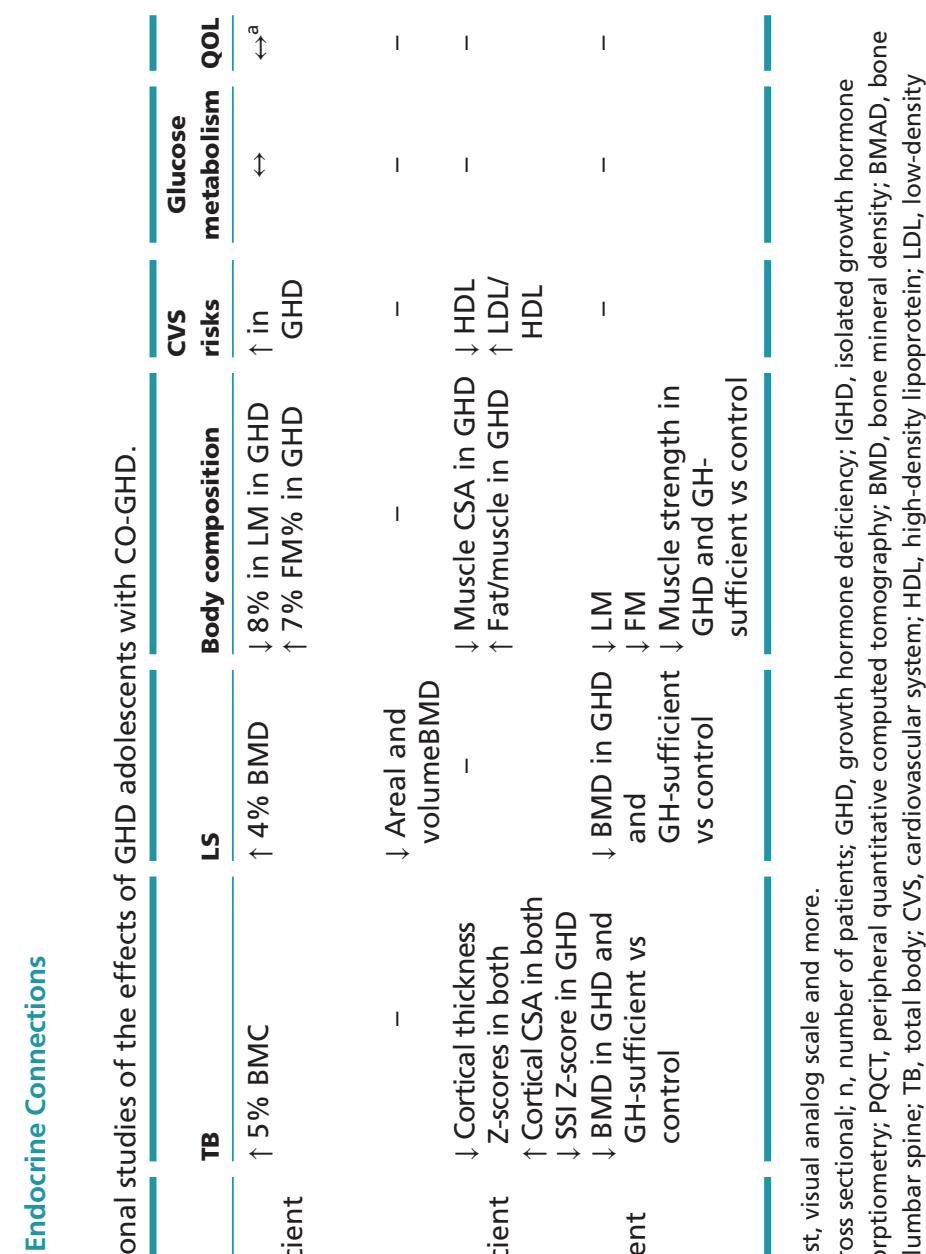

6-12 months off GH therapy was associated with a lower femoral neck (FN)-BMD, and therefore, a firm recommendation of a safe duration off rhGH replacement therapy with regard to BMD cannot be made (22).

Dose dependency with regard to the impacts of rhGH on bone mass has only been studied in two studies; a 2-year randomised controlled trial found a higher dose $(25 \mu \mathrm{g} / \mathrm{kg} /$ day) of $\mathrm{rhGH}$ impact differently in favour of bone mass than a lower dose $(12.5 \mu \mathrm{g} / \mathrm{kg} /$ day) (16), when no significant difference was found in another similar study over same period (15).

It is noteworthy that among all the studies reported in Table 2, there was a considerable variability in definition of GHD during transition and retesting in terms of stimulated GH peak cut-offs, population heterogeneity between isolated GHD/multiple pituitary hormone deficiencies (MPHD) and aetiologies of GHD, and duration of discontinuation of rhGH after final height, rhGH dose during childhood and after final height. In addition, measurement of bone density using DXA in children and adolescents with CO-GHD is challenging by confounding effects of body size and composition, with no consensus as to what is the optimal adjustment to express bone densitometry, additional to the lack of reference data that adjusts for different confounding factors of growthimpaired children and adolescents (23). Therefore, this variation may substantially affect the interpretation of the results, limiting the analysis to certain groups of patients with the greatest benefit from the rhGH treatment during transition.

It is also increasingly recognised that the bone health and fracture prediction is dependent not only on bone density but also on bone geometry and microarchitecture (24). The consequences of GHD and rhGH replacement on bone geometry and structure in subjects with CO-GHD have been investigated in few studies demonstrating reduced cortical area and thickness but normal cortical and trabecular density at time of diagnosis during childhood which was significantly reduced after 1 year of rhGH treatment (25). At final height and after discontinuation of rhGH, marked lower height corrected cortical thickness and wider endosteal circumference but a normal cortical and trabecular density compared with a healthy reference population (26). Two years of rhGH replacement results in a significant increase in cortical thickness compared with non-treated control group of young adults with CO-GHD (27), when a significant reduction in cortical bone area and thickness in untreated CO-GHD adults compared with AO-GHD was reported elsewhere (28). One recent study with more advanced

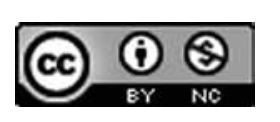

This work is licensed under a Creative Commons Attribution-NonCommercial 4.0 International License. 


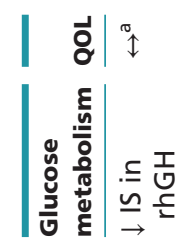

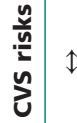
七 $\boldsymbol{\xi} \rightarrow$

๓

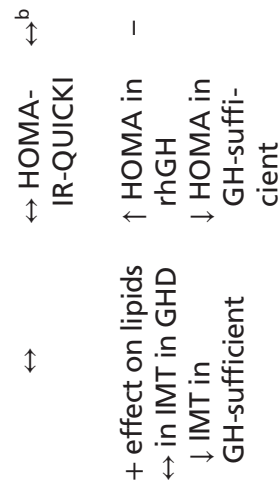

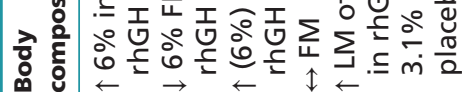

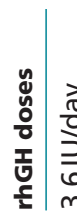

$\frac{\sqrt{1}}{\frac{1}{0}}$

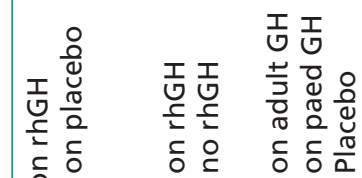

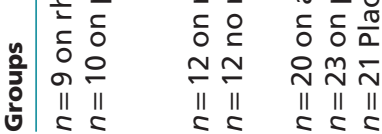

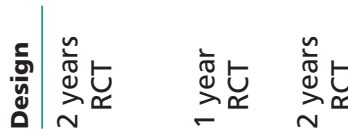

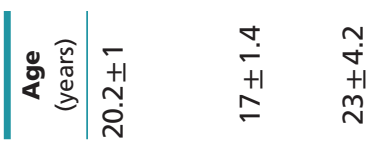

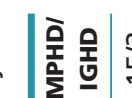

है $|\geq| \stackrel{\infty}{\sim}$

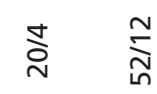

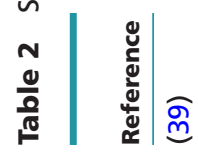

.5

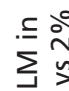

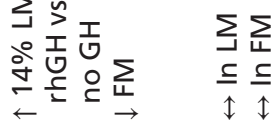

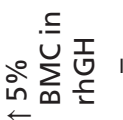

工ٓ⿱

$\subseteq$

$\sum_{\infty}^{u}$

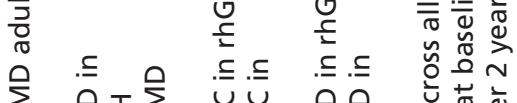

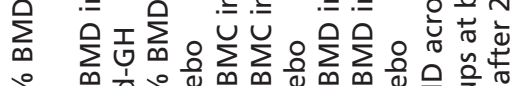

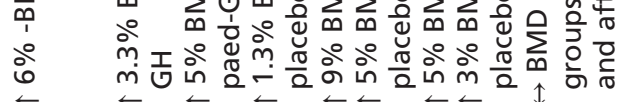

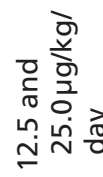

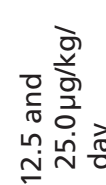

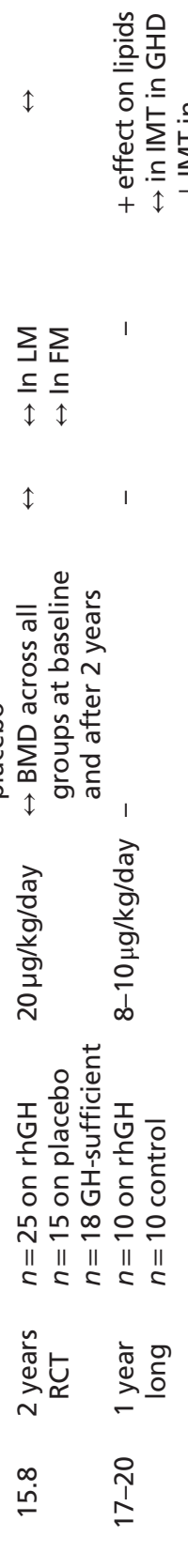

ป
工ٓ언

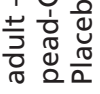

ᄃㄷㄷㅇ

ํํำ

II II II

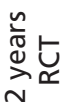

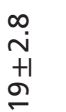

곤

ส

䰹全昏

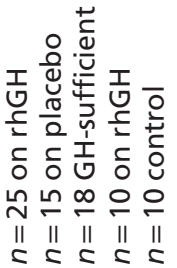

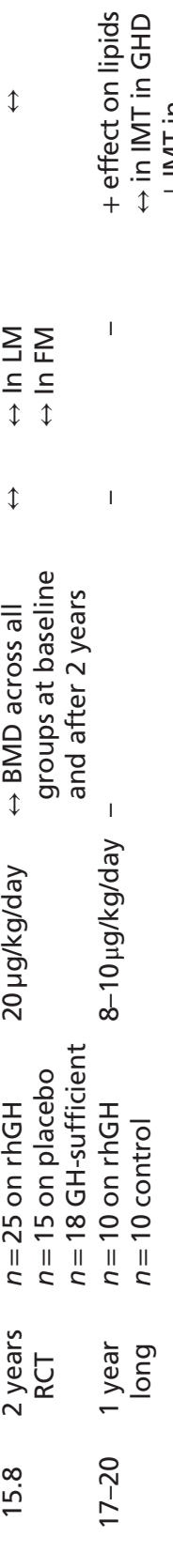

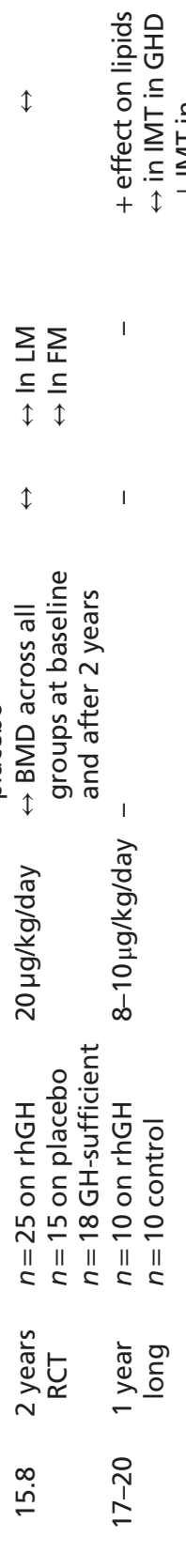

$\stackrel{m}{m} \quad n$

i 응

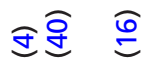

() 2016 The authors

http://www.endocrineconnections.org DOI: 10.1530/EC-16-0024

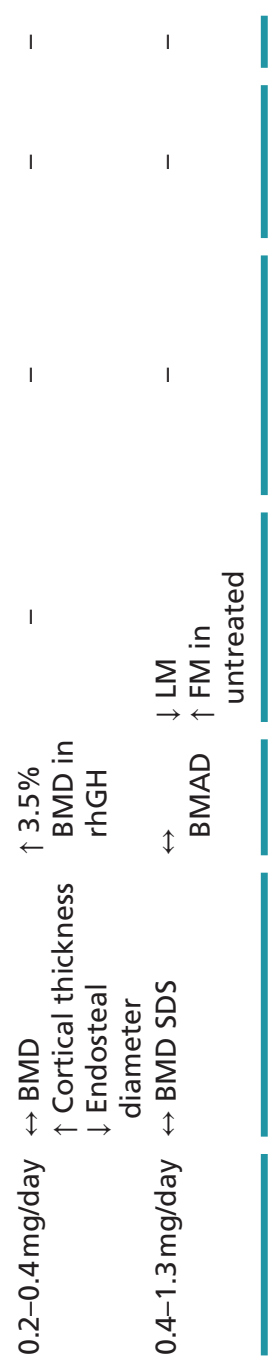

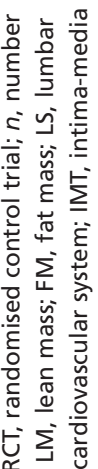

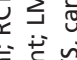

䒠

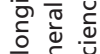

흐 용.

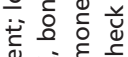

焉部

言空

过 흥

돈 눙응

范

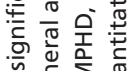

ㅇ ह

बें 눈

هั

d

is

ब。

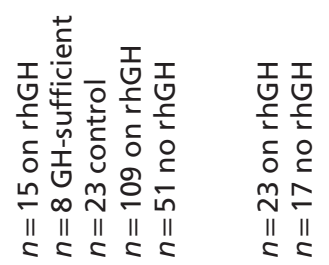

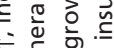

它

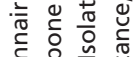

은

J 0

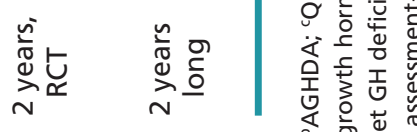

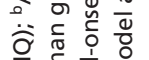

牙

凶ै

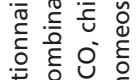

党

동용

贾

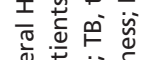

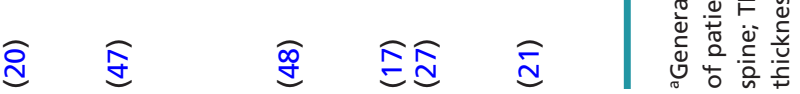


imaging (high-resolution magnetic resonance imaging (micro-MRI)) investigated the bone structure of ten young adults with hypogonadism and/or CO-GHD and reported that the ratio of apparent bone volume to total volume (appBV/TV) and apparent trabecular number (appTbN) was significantly lower in GHD than in the age-matched control group (29), although the relationship between trabecular size and number to bone fragility and fracture risk has not been established yet.

Risk of fracture: Although data on the association between bone density and fractures in children are limited, it is generally established that the fracture risk may be higher in healthy children and adolescents who have low BMC and bone accrual $(30,31)$. The association between GHD, low bone mass and subsequent fracture risk in adolescents and young adults with CO-GHD is less clear than that observed in adults with GHD and hypopituitarism $(32,33)$. However, in these studies, it was not known if that is a result of being GH deficient per se or due to other pituitary hormone deficiencies. Accordingly, other studies showed no evidence that isolated GHD (IGHD) may increase fracture risk $(34,35)$. With regard to the impact of rhGH replacement therapy on fracture rates, childhood studies suggest a protective effect of rhGH treatment in children with GHD with a four-fold decrease in fracture frequency from diagnosis to final height compared with matched healthy controls, but fracture prevalence increased to $3 \%$ at final height particularly in those with reduced lumbar BMD (Z-score <1) (12). Studies in adults involving both $\mathrm{CO}$ - and AO-GHD reported a lower incidence of fracture risk in CO-GHD compared with AO- $(32,34,36)$, with a double incidence of non-osteoporotic fracture in women with CO-GHD compared with men with CO-GHD despite continuation of rhGH treatment (36) (Table 3). In view of these studies, CO-GHD was queried as a cause of osteoporosis due to the lack of evidence for increased fracture risk in children and adults with CO-GHD or severe GH resistance (37).

To summarise this section, data thus far demonstrate contradictory results with most studies, but not all, showing a small increase in bone density and mineralisation during rhGH therapy in transition. However, the extent of GHD and replacement with regard to bone density and architecture is unclear. Using more advanced non-invasive imaging tools, which assess bone quality, may provide a greater insight into the effects of GHD and rhGH on bone.

In addition, there is an insufficient evidence of increased fracture risk in patients with CO-GHD as the reporting of the risk of fracture in GHD had considerable 
limitations. Therefore, it remains unclear whether early adulthood rhGH treatment would offer protection from osteoporosis and fracture risk in late adulthood. Prospective long-term follow-up studies are still lacking.

\section{Body composition and muscle strength}

During transition, studies indicate that patients who were reconfirmed to have persistent GHD and discontinued rhGH in the transition period showed decreased lean mass (LM) (-8\%) and increased fat mass (FM) (10-17\%) compared with either sufficient or those who continued rhGH after 2 years of observation $(21,38,39,40)$. A study measured the early changes in body composition in CO-GHD patients after a median of 6 months after cessation of rhGH in patients who attained final height. The authors stated that patients with persistent GHD $(n=37)$ had a significantly lower muscle cross-sectional area (CSA) Z-score $(-0.24 \pm 1.6$ vs $0.44 \pm 1.42, P<0.03)$, a two-fold increase in fat CSA $\left(1329+100 \mathrm{~mm}^{2}\right.$ vs $878+91$ $\mathrm{mm}^{2}$ ) compared with patients who were no longer $\mathrm{GH}$ deficient at final height (26). Recommencement of rhGH therapy was documented to result in a marked improvement in body composition, with an increase in LM by $14 \%$, and a reduction in FM by $-7 \%$ over 2 years of replacement $(16,41)$, yet long-term studies are scarce in determining the sustainability of these changes. A study by Mauras and coworkers is the only one that showed no significant difference in the changes of LM and FM from baseline to 2 year between continuation of rhGH as compared with placebo-treated or control subjects (20).

In terms of the relationship between CO-GHD, rhGH and muscle strength, it has been reported that discontinuation of rhGH in CO-GHD for 2 years has potentially negative consequences on muscular strength in some studies $(3,42)$, but not all $(20,39)$. From a recently published cross-sectional study investigating muscle strength and body composition of 18 males with CO-GHD (aged 18-30 years), of those, 9 (4-IGHD) were reconfirmed to have GHD after re-evaluating them at final height during transition. This study suggested that muscle strength as measured by an isokinetic dynamometer was lower in those with persistent GHD compared with sufficient and healthy controls $(P<0.05)(13)$. However, data so far do not support the use of rhGH therapy to increase muscle strength during transition and young adulthood $(16,21,39)$.

The majority of research has shown favourable differences in body composition with recommencing rhGH during transition, although encouraging further research in the field with long-term follow-up is needed.

\section{Cardiovascular risks and glucose metabolism}

Epidemiological evidence shows negative effects of GHD on cardiovascular risk factors including unfavourable lipid profiles, hypercoagulability, atherosclerosis and endothelial dysfunction, which could contribute to increased morbidity and mortality of adults with GHD and hypopituitarism without rhGH therapy (43), with a higher hazard ratio in AO-GHD compared with CO-GHD (3.0 (2.1-4.4) vs 1.4 (1.0-1.8), respectively (44). Cardiovascular risk in CO-GHD and benefits of rhGH have been documented during childhood $(45,46)$ and adolescence (47).

Lipid profiles: It has been well established that discontinuation of rhGH therapy after final height results in an increase in unfavourable lipid profile $(26,41,48$, 49), while the effect of restarting rhGH therapy remains unclear. Some studies have shown reversal in the levels of unfavourable lipid profiles (50), whereas others report no change in lipid profile on either cessation or continuation of rhGH therapy during transition $(16,20,40)$. A study of KIMS database (Pfizer International Metabolic Database) reported that those who were older at first starting childhood rhGH (short duration of childhood rhGH replacement) and had a longer time off rhGH during transition were more likely to have higher total cholesterol and triglyceride levels during transition (51).

Cardiac structure and performance: At final height, cross-sectional echocardiographic studies indicate that all cardiac dimensions of adolescents with GHD who were treated with rhGH during childhood were significantly smaller than their age- and sex-matched healthy controls after withdrawal of rhGH $(5.7 \pm 4.5$ years $)$, whereas reinstituting rhGH results in a significant increase in LV mass and LV mass index after 16-24 months (52) with improvement in endothelial function within the first 6 months of restarting rhGH (53).

There is also conflicting data on alterations in carotid artery intima-media thickness (IMT), a surrogate marker of early atherosclerosis with increasing in IMT thickness, in subjects with CO-GHD. Murata and coworkers showed a significantly higher IMT in adults with CO-GHD compared with both adults with AO-GHD and healthy controls (54). However, this alteration in IMT was not evident in adolescents with CO-GHD during and after discontinuation of $\operatorname{rhGH}(48,55)$. A study involving 23 subjects with CO-GHD (14-IGHD) (aged 15-20 years)
This work is licensed under a Creative Commons Attribution-NonCommercial 4.0 International License. 
showed that 6 months off rhGH in adolescents with confirmed GHD did not result in a significant alteration of the common carotid arteries, whereas in adolescents who were not confirmed to have GHD, IMT increased during rhGH treatment and reversed to normal 12 months after rhGH withdrawal (48).

In summary, the current evidence suggests that discontinuation of rhGH during transition is associated with a pro-atherogenic lipid profile; however, the effects of recommencement of rhGH treatment and a prolonged period off treatment are less clear. There is no evidence demonstrating that discontinuation of rhGH therapy during transition has any detrimental consequences on the cardiovascular system in the short or long term.

Glucose metabolism: Few studies have investigated CO-GHD and its replacement on insulin and glucose metabolism during transition in relation to concomitant changes in body composition and metabolism. After cessation of rhGH at final height, some studies reported an increase in insulin sensitivity as estimated by either means of a hyperinsulinemic euglycaemic clamp (56) or homeostasis model assessment (HOMA) (40) and an increase in fasting glucose (39) in those who had persistent GHD, with similar changes reported elsewhere in those who were not confirmed to be GH deficient at final height (57). Inversely, significantly impaired insulin resistance as measured by HOMA was recorded within 6 months off rhGH, but returned to baseline levels after 6 months after restarting rhGH replacement (48). At 2 years of resuming rhGH therapy during transition, there was an insignificant or limited effect on insulin residence, insulin sensitivity and glycosylated haemoglobin (HbA1c) $(16,20,56)$. In addition to the variation in techniques used to assess glucose homeostasis in these studies, other factors, particularly body compositions and short-term duration, results in limited evidence with regards to impairment of glucose homeostasis in GHD and rhGH replacement during transition. Long-term studies are necessary to identify the influence of different aspects of GHD and replacement on glucose homeostasis during transition.

Generally, there is weak evidence that GHD or rhGH replacement induces an increase in the risk of type 2 diabetes (T2DM) in subjects with GHD. With regard to GHD, the KIMS database has demonstrated that the prevalence of T2DM in untreated adults with AO-GHD and hypopituitarism was higher than expected with an overall standardised prevalence proportion ratio (1.13 (95\% CI: $1.04-1.23 \%)$ ), which was largely to be explained by high
BMI and the adverse body composition (58). In terms of rhGH replacement, there is an uncertain relationship between rhGH treatment and the risk of T2DM, in particular in those with GHD, and whether rhGH therapy leads to increased risk of diabetes has not been established yet. Paediatric studies demonstrated modest increases in the incidence of T2DM in rhGH-treated children with predisposed risks relative to the general population, but not in those with GHD individually $(59,60)$.

In conclusion, in GHD, there is insufficient evidence available to conclude whether or not rhGH therapy in childhood or transition alters insulin sensitivity and increases the risk of T2DM in adulthood. More research is needed to clarify the elements of the dual effects of GH during transition in adolescents with CO-GHD with regards to both the impact on body composition/BMI and insulin resistance.

\section{Quality of life}

The health-related quality of life (QoL) issue has emerged as an important aspect in consideration of rhGH therapy in adulthood, but not during childhood or transition (8). In relation to QoL in individuals with CO-GHD, some studies reported that children and adolescents with GHD have some difficulties with psychosocial functioning, mood, behaviour and cognitive ability (61) despite the achievement of acceptable final height (62). A retrospective study suggested that adolescents with CO-GHD who were not treated with rhGH after attaining final height have some psychological difficulties with self-confidence and social contact, and this was worse in those who were either rhGH-treated after the age of 12 years or those who were shorter at the start of treatment (61). A report from the KIMS database showed a positive relationship between height gain during childhood treatment and improvement in QoL at transition and an inverse relationship between QoL and duration off rhGH therapy with a longer period off rhGH associated with a poorer QoL (51). Re-instituting rhGH treatment has a significant positive change in healthrelated QoL aspects $(51,63)$. However, longitudinal studies evaluated the effects of discontinuation and resumption of rhGH treatment on QoL in young adults with CO-GHD and showed that discontinuation of rhGH treatment for 1 year leads to a decrease in QoL within 6 months, which is counteracted in 3-6 months after re-initiating rhGH therapy $(6,64)$. This was disputed in follow-up and RCT studies showing that QoL is less effected in adolescents with GHD measured after discontinuation rhGH at final height (63) with no difference in being off rhGH therapy and after re-commencing $\operatorname{rhGH}(16,20,65)$.

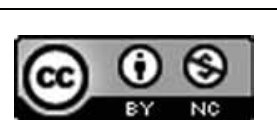

This work is licensed under a Creative Commons Attribution-NonCommercial 4.0 International License. 
However, using different questionnaire tools (generic and disease-specific questionnaires) which assess different dimensions of health-related quality of life in adolescents with CO-GHD makes comparisons of the outcomes of these studies difficult.

In summary, there is variability in the assessment of QoL by different studies in terms of the instruments used and the effects measured which may reflect the different outcome results in QoL. In addition, QoL is multifactorial and factors such as short stature combined with other pituitary hormones deficiency may influence QoL in this particular group of patients. To date, there is no clear consensus on the appropriate QoL measurement tools in children and adolescents with GHD. Therefore, there is currently no evidence of reduced QoL that rhGH may have beneficial effects on QoL in subject with CO-GHD during transition.

\section{Conclusions}

GHD is an important condition that has detrimental effects on both physical and psychological health throughout life, whereas rhGH therapy shows benefits in both children and young adults with GHD throughout each stage of their life. It seems from the current data that rhGH has less direct impact on bone density, with a greater impact on body composition and cardiovascular risk factors, including improvement in serum lipid profiles, and to a lesser extent on insulin sensitivity and QoL. Even with scarce evidence, substantial short-term studies during transition revealed that untreated GHD has a risk of alteration in somatic and metabolic consequences, although it is difficult to establish whether these mild alterations represent the early long-term consequences and whether subsequent rhGH treatment improves long-term health. Larger studies of longer duration of rhGH therapy will be required to determine whether the metabolic alterations in adolescent GH-deficient patients persist in later adulthood and if recommencement of rhGH therapy has a positive impact on these aspects.

\section{Declaration of interest}

The authors declare that there is no conflict of interest that could be perceived as prejudicing the impartiality of this review.

\section{Funding}

This work did not receive any specific grant from any funding agency in the public, commercial, or not-for-profit sector.

\section{Acknowledgements}

M Ahmid's PhD studies are currently supported by the Government of Libya.

\section{References}

1 National Institute for Clinical Excellence. Human growth hormone (somatropin) for the treatment of growth failure in children (2010). NICE technology appraisal guidance [TA188]. (accessed December 2015). (available at: http://guidance.nice.org.uk/TA188).

2 Philip S, Howat I, Carson M, Booth A, Campbell K, Grant D, Patterson C, Schofield C, Bevan J, Patrick A, et al. An audit of growth hormone replacement for GH-deficient adults in Scotland. Clinical Endocrinology 201378 571-576. (doi:10.1111/cen.12017)

3 Hulthen L, Bengtsson BA, Sunnerhagen KS, Hallberg L, Grimby G \& Johannsson G. GH is needed for the maturation of muscle mass and strength in adolescents. Journal of Clinical Endocrinology \& Metabolism 200186 4765-4770. (doi:10.1210/jcem.86.10.7897)

4 Drake WM, Carroll PV, Maher KT, Metcalfe KA, Camacho-Hubner C, Shaw NJ, Dunger DB, Cheetham TD, Savage MO \& Monson JP. The effect of cessation of growth hormone (GH) therapy on bone mineral accretion in GH-deficient adolescents at the completion of linear growth. Journal of Clinical Endocrinology \& Metabolism 200388 1658-1663. (doi:10.1210/jc.2003-030990)

5 Fideleff HL, Jonsson B, Koltowska-Haggstrom M, Boguszewski MC, Wilton P \& Boquete HR. GH deficiency during the transition period: clinical characteristics before and after GH replacement therapy in two different subgroups of patients. Journal of Pediatric Endocrinology and Metabolism 201225 97-105. (doi:10.1515/jpem.2011.349)

6 Stouthart PJ, Deijen JB, Roffel M \& Delemarre-van de Waal HA. Quality of life of growth hormone (GH) deficient young adults during discontinuation and restart of GH therapy. Psychoneuroendocrinology 200328 612-626. (doi:10.1016/S0306-4530(02)00045-8)

7 Paediatric Formulary Committee. BNF for Children 59. London, UK: BMJ Group, Pharmaceutical Press, and RCPCH Publications, 2010.

8 National Institute for Clinical Excellence. Human growth hormone (somatropin) in adults with growth hormone deficiency (2003). NICE technology appraisal guidance [TA64]. (accessed December 2015). (available at: http://guidance.nice.org.uk/TA64).

9 Saggese G, Baroncelli GI, Bertelloni S \& Barsanti S. The effect of longterm growth hormone $(\mathrm{GH})$ treatment on bone mineral density in children with GH deficiency. Role of GH in the attainment of peak bone mass. Journal of Clinical Endocrinology \& Metabolism 199681 3077-3083. (doi:10.1210/jcem.81.8.8768878)

10 Ogle GD, Moore B, Lu PW, Craighead A, Briody JN \& Cowell CT. Changes in body composition and bone density after discontinuation of growth hormone therapy in adolescence: an interim report. Acta Paediatrica 1994399 3-7. (doi:10.1111/j.1651-2227.1994.tb13274.x)

11 Fors H, Bjarnason R, Wiren L, Albertsson-Wikland K, Bosaeus I, Bengtsson BA \& Johansson G. Currently used growth-promoting treatment of children results in normal bone mass and density. A prospective trial of discontinuing growth hormone treatment in adolescents. Clinical Endocrinology 200155 617-624. (doi:10.1046/ j.1365-2265.2001.01386.x)

12 Baroncelli GI, Bertelloni S, Sodini F \& Saggese G. Lumbar bone mineral density at final height and prevalence of fractures in treated children with GH deficiency. Journal of Clinical Endocrinology \& Metabolism 200287 3624-3631. (doi:10.1210/jcem.87.8.8754)

13 de Jesus Modesto M, Amer NM, Erichsen O, Hernandez S, Dos Santos CD, de Carvalho JA, Pereira RM, Franca SN \& De Lacerda L. Muscle strength and body composition during the transition phase in patients treated with recombinant GH to final height. Journal of Pediatric Endocrinology \& Metabolism 201427 813-820. (doi:10.1515/ jpem-2013-0317)

14 Baroncelli GI, Bertelloni S, Sodini F \& Saggese G. Longitudinal changes of lumbar bone mineral density (BMD) in patients with GH deficiency after discontinuation of treatment at final height; timing and peak values for lumbar BMD. Clinical Endocrinology 200460 175-184. (doi:10.1046/j.1365-2265.2003.01949.x) http://www.endocrineconnections.org
DOI: 10.1530/EC-16-0024

C) 2016 The authors $\odot 2016$ The authors
Published by Bioscientifica Ltd
This work is licensed under a Creative Commons Attribution-NonCommercial 4.0 International License. 
15 Shalet SM, Shavrikova E, Cromer M, Child CJ, Keller E, Zapletalova J, Moshang T, Blum WF, Chipman JJ, Quigley CA, et al. Effect of growth hormone (GH) treatment on bone in postpubertal GH-deficient patients: a 2-year randomized, controlled, dose-ranging study. Journal of Clinical Endocrinology \& Metabolism 200388 4124-4129. (doi:10.1210/jc.2003-030126)

16 Underwood LE, Attie KM, Baptista J \& Genentech Collaborative Study Group. Growth hormone (GH) dose-response in young adults with childhood-onset GH deficiency: a two-year, multicenter, multipledose, placebo-controlled study. Journal of Clinical Endocrinology \& Metabolism 200388 5273-5280. (doi:10.1210/jc.2003-030204)

17 Conway GS, Szarras-Czapnik M, Racz K, Keller A, Chanson P, Tauber M \& Zacharin M. Treatment for 24 months with recombinant human GH has a beneficial effect on bone mineral density in young adults with childhood-onset GH deficiency. European Journal of Endocrinology 2009160 899-907. (doi:10.1530/EJE-08-0436)

18 Sabatier JP, Guaydier-Souquieres G, Laroche D, Benmalek A, Fournier L, Guillon-Metz F, Delavenne J \& Denis AY. Bone mineral acquisition during adolescence and early adulthood: a study in 574 healthy females 10-24 years of age. Osteoporosis International 19966 141-148. (doi:10.1007/bf01623938)

19 Bonjour J, Theintz G, Buchs B, Slosman D \& Rizzoli R. Critical years and stages of puberty for spinal and femoral bone mass accumulation during adolescence. Journal of Clinical Endocrinology \& Metabolism 199173 555-563. (doi:10.1210/jcem-73-3-555)

20 Mauras N, Pescovitz OH, Allada V, Messig M, Wajnrajch MP \& Lippe B. Limited efficacy of growth hormone $(\mathrm{GH})$ during transition of GH-deficient patients from adolescence to adulthood: a phase III multicenter, double-blind, randomized two-year trial. Journal of Clinical Endocrinology \& Metabolism 200590 3946-3955. (doi:10.1210/ jc.2005-0208)

21 Boot AM, van der Sluis IM, Krenning EP \& SMPF de Muinck KeizerSchrama. Bone mineral density and body composition in adolescents with childhood-onset growth hormone deficiency. Hormone Research 200971 364-371. (doi:10.1159/000223422)

22 Tritos NA, Hamrahian AH, King D, Greenspan SL, Cook DM, Jonsson PJ, Wajnrajch MP, Koltowska-Haggstrom M \& Biller BM. A longer interval without GH replacement and female gender are associated with lower bone mineral density in adults with childhoodonset GH deficiency: a KIMS database analysis. European Journal of Endocrinology 2012167 343-351. (doi:10.1530/EJE-12-0070)

23 Crabtree NJ, Arabi A, Bachrach LK, Fewtrell M, El-Hajj Fuleihan G, Kecskemethy HH, Jaworski M, Gordon CM \& International Society for Clinical Densitometry. Dual-energy X-ray absorptiometry interpretation and reporting in children and adolescents: the revised 2013 ISCD Pediatric Official Positions. Journal of Clinical Densitometry 201417 225-242. (doi:10.1016/j.jocd.2014.01.003)

24 Bishop N, Arundel P, Clark E, Dimitri P, Farr J, Jones G, Makitie O, Munns CF \& Shaw N. Fracture prediction and the definition of osteoporosis in children and adolescents: the ISCD 2013 Pediatric Official Positions. Journal of Clinical Densitometry 201417 275-280. (doi:10.1016/j.jocd.2014.01.004)

25 Schweizer R, Martin DD, Schwarze CP, Binder G, Georgiadou A, Ihle J $\&$ Ranke MB. Cortical bone density is normal in prepubertal children with growth hormone (GH) deficiency, but initially decreases during GH replacement due to early bone remodeling. Journal of Clinical Endocrinology \& Metabolism 200388 5266-5272. (doi:10.1210/ jc.2003-030432)

26 Bechtold S, Bachmann S, Putzker S, Dalla Pozza R \& Schwarz HP. Early changes in body composition after cessation of growth hormone therapy in childhood-onset growth hormone deficiency. Journal of Clinical Densitometry 201114 471-477. (doi:10.1016/j. jocd.2011.05.001)

27 Hyldstrup L, Conway GS, Racz K, Keller A, Chanson P, Zacharin M, Lysgaard AL, Andreasen AH \& Kappelgaard AM. Growth hormone effects on cortical bone dimensions in young adults with childhood-onset growth hormone deficiency. Osteoporosis International 201223 2219-2226. (doi:10.1007/s00198-011-1854-0)

28 Murray RD, Adams JE \& Shalet SM. A densitometric and morphometric analysis of the skeleton in adults with varying degrees of growth hormone deficiency. Journal of Clinical Endocrinology \& Metabolism 200691 432-438. (doi:10.1210/jc.2005-0897)

29 McComb C, Harpur A, Yacoubian C, Leddy C, Anderson G, Shepherd S, Perry C, Shaikh MG, Foster J \& Ahmed SF. MRI-based abnormalities in young adults at risk of adverse bone health due to childhood-onset metabolic \& endocrine conditions. Clinical Endocrinology 201480 811-817. (doi:10.1111/cen.12367)

30 Goulding A. Risk factors for fractures in normally active children and adolescents. Medicine and Sport Science 200751 102-120. (doi:10.1159/000103007)

31 Clark EM, Tobias JH \& Ness AR. Association between bone density and fractures in children: a systematic review and meta-analysis. Pediatrics 2006117 e291-e297. (doi:10.1542/peds.2005-1404)

32 Wuster C, Abs R, Bengtsson BA, Bennmarker H, Feldt-Rasmussen U, Hernberg-Stahl E, Monson JP, Westberg B, Wilton P, Kims Study Group \& KIMS International Board. The infuence of growth hormone deficiency, growth hormone replacement therapy, and other aspects of hypopituitarism on fracture rate and bone mineral density. Journal of Bone and Mineral Research 200116 398-405. (doi:10.1359/ jbmr.2001.16.2.398)

33 Rosen T, Wilhelmsen L, Landin-Wilhelmsen K, Lappas G \& Bengtsson BA. Increased fracture frequency in adult patients with hypopituitarism and GH deficiency. European Journal of Endocrinology 1997137 240-245. (doi:10.1530/eje.0.1370240)

34 Abs R, Mattsson AF, Bengtsson BA, Feldt-Rasmussen U, Goth MI, Koltowska-Haggstrom M, Monson JP, Verhelst J, Wilton P \& KIMS Study Group.Isolated growth hormone (GH) deficiency in adult patients: baseline clinical characteristics and responses to $\mathrm{GH}$ replacement in comparison with hypopituitary patients. A subanalysis of the KIMS database. Growth Hormone \& IGF Research 2005 15 349-359. (doi:10.1016/j.ghir.2005.06.018)

35 Bouillon R, Koledova E, Bezlepkina O, Nijs J, Shavrikhova E, Nagaeva E, Chikulaeva O, Peterkova V, Dedov I, Bakulin A, et al. Bone status and fracture prevalence in Russian adults with childhoodonset growth hormone deficiency. Journal of Clinical Endocrinology \& Metabolism 200489 4993-4998. (doi:10.1210/jc.2004-0054)

36 Holmer H, Svensson J, Rylander L, Johannsson G, Rosen T, Bengtsson BA, Thoren M, Hoybye C, Degerblad M, Bramnert M, et al. Fracture incidence in $\mathrm{GH}$-deficient patients on complete hormone replacement including GH. Journal of Bone and Mineral Research 2007 22 1842-1850. (doi:10.1359/jbmr.070811)

37 Hogler W \& Shaw N. Childhood growth hormone deficiency, bone density, structures and fractures: scrutinizing the evidence. Clinical Endocrinology 201072 281-289. (doi:10.1111/j.13652265.2009.03686.x)

38 Johannsson G \& Albertsson-Wikland K. Discontinuation of growth hormone $(\mathrm{GH})$ treatment: metabolic effects in GH-deficient and GH-sufficient adolescent patients compared with control subjects. Journal of Clinical Endocrinology \& Metabolism 199984 4516-4524. (doi:10.1210/jc.84.12.4516)

39 Vahl N, Juul A, Jorgensen JO, Orskov H, Skakkebaek NE \& Christiansen JS. Continuation of growth hormone $(\mathrm{GH})$ replacement in GH-deficient patients during transition from childhood to adulthood: a two-year placebo-controlled study. Journal of Clinical Endocrinology \& Metabolism 200085 1874-1881. (doi:10.1210/jc.85.5.1874)

40 Carroll PV, Drake WM, Maher KT, Metcalfe K, Shaw NJ, Dunger DB, Cheetham TD, Camacho-Hubner C, Savage MO \& Monson JP. Comparison of continuation or cessation of growth hormone (GH) therapy on body composition and metabolic status in adolescents with severe GH deficiency at completion of linear growth. Journal of Clinical Endocrinology \& Metabolism 200489 3890-3895. (doi:10.1210/jc.2003-031588) 
41 Attanasio AF, Shavrikova E, Blum WF, Cromer M, Child CJ, Paskova M, Lebl J, Chipman JJ, Shalet SM \& Hypopituitary Developmental Outcome Study Group. Continued growth hormone (GH) treatment after final height is necessary to complete somatic development in childhood-onset GH-deficient patients. Journal of Clinical Endocrinology \& Metabolism 200489 4857-4862. (doi:10.1016/s0084-3741(08)70464-5)

42 Rutherford OM, Jones DA, Round JM, Buchanan CR \& Preece MA. Changes in skeletal muscle and body composition after discontinuation of growth hormone treatment in growth hormone deficient young adults. Clinical Endocrinology 199134 469-475. (doi:10.1111/j.1365-2265.1991.tb00327.x)

43 Rosen T \& Bengtsson BA. Premature mortality due to cardiovascular disease in hypopituitarism. Lancet 1990336 285-288. (doi:10.1016/0140-6736(90)91812-O)

44 Stochholm K, Gravholt CH, Laursen T, Laurberg P, Andersen M, Kristensen L $\varnothing$, Feldt-Rasmussen U, Christiansen JS, Frydenberg M \& Green A. Mortality and GH deficiency: a nationwide study. European Journal of Endocrinology 2007 157 9-18. (doi:10.1530/EJE-07-0013)

45 Capalbo D, Lo Vecchio A, Farina V, Spinelli L, Palladino A, Tiano C, Lettiero T, Lombardi G, Colao A \& Salerno M. Subtle alterations of cardiac performance in children with growth hormone deficiency: results of a two-year prospective, case-control study. Journal of Clinical Endocrinology \& Metabolism 200994 3347-3355. (doi:10.1210/jc.2008-2639)

46 Salerno M, Esposito V, Farina V, Radetti G, Umbaldo A, Capalbo D, Spinelli L, Muzzica S, Lombardi G \& Colao A. Improvement of cardiac performance and cardiovascular risk factors in children with GH deficiency after two years of GH replacement therapy: an observational, open, prospective, case-control study. Journal of Clinical Endocrinology \& Metabolism 200691 1288-1295. (doi:10.1210/jc.2005-0981)

47 Colao A, Di Somma C, Salerno M, Spinelli L, Orio F \& Lombardi G. The cardiovascular risk of GH-deficient adolescents. Journal of Clinical Endocrinology \& Metabolism 200287 3650-3655. (doi:10.1210/ jc.87.8.3650)

48 Colao A, Di Somma C, Rota F, Di Maio S, Salerno M, Klain A, Spiezia S \& Lombardi G. Common carotid intima-media thickness in growth hormone (GH)-deficient adolescents: a prospective study after GH withdrawal and restarting GH replacement. Journal of Clinical Endocrinology \& Metabolism $2005902659-2665$. (doi:10.1210/jc.2004-1844)

49 Capalbo D, Esposito A, Di Mase R, Barbieri F, Parenti G, Vajro P, Pignata C \& Salerno M. Update on early cardiovascular and metabolic risk factors in children and adolescents affected with growth hormone deficiency. Minerva Endocrinologica 201237 379-389.

50 Aimaretti G, Corneli G, Rovere S, Croce CG, Ghigo E \& Procopio M. Is GH therapy useful to preserve bone mass in transition-phase patients with GH deficiency? Journal of Endocrinological Investigation 200528 28-32.

51 Koltowska-Haggstrom M, Geffner ME, Jonsson P, Monson JP, Abs R, Hana V, Hoybye C \& Wollmann HA. Discontinuation of growth hormone $(\mathrm{GH})$ treatment during the transition phase is an important factor determining the phenotype of young adults with nonidiopathic childhood-onset GH deficiency. Journal of Clinical Endocrinology \& Metabolism 201095 2646-2654. (doi:10.1210/jc.2009-2013)

52 Feinberg MS, Scheinowitz M \& Laron Z. Cardiac dimension and function in patients with childhood onset growth hormone deficiency, before and after growth hormone retreatment in adult age. American Heart Journal 2003145 549-553. (doi:10.1067/mhj.2003.175)

53 Amato G, Carella C, Fazio S, La Montagna G, Cittadini A, Sabatini D, Marciano-Mone C, Sacca L \& Bellastella A. Body composition, bone metabolism, and heart structure and function in growth hormone
(GH)-deficient adults before and after GH replacement therapy at low doses. Journal of Clinical Endocrinology \& Metabolism 199377 1671-1676. (doi:10.1210/jc.77.6.1671)

54 Murata M, Kaji H, Mizuno I, Sakurai T, Iida K, Okimura Y \& Chihara K. A study of carotid intima-media thickness in GH-deficient Japanese adults during onset among adults and children. European Journal of Endocrinology 2003148 333-338. (doi:10.1530/ eje.0.1480333)

55 Lanes R, Gunczler P, Lopez E, Esaa S, Villaroel O \& Revel-Chion R. Cardiac mass and function, carotid artery intima-media thickness, and lipoprotein levels in growth hormone-deficient adolescents. Journal of Clinical Endocrinology \& Metabolism 200186 1061-1065. (doi:10.1210/jc.86.3.1061)

56 Norrelund H, Vahl N, Juul A, Moller N, Alberti KG, Skakkebaek NE, Christiansen JS \& Jorgensen JO. Continuation of growth hormone (GH) therapy in GH-deficient patients during transition from childhood to adulthood: impact on insulin sensitivity and substrate metabolism. Journal of Clinical Endocrinology \& Metabolism 200085 1912-1917. (doi:10.1210/jc.85.5.1912)

57 Prodam F, Savastio S, Genoni G, Babu D, Giordano M, Ricotti R, Aimaretti G, Bona G \& Bellone S. Effects of growth hormone (GH) therapy withdrawal on glucose metabolism in not confirmed GH deficient adolescents at final height. PLoS ONE 20149 e87157. (doi:10.1371/journal.pone.0087157)

58 Abs R, Mattsson AF, Thunander M, Verhelst J, Goth MI, Wilton P, Koltowska-Haggstrom M \& Luger A. Prevalence of diabetes mellitus in 6050 hypopituitary patients with adult-onset GH deficiency before GH replacement: a KIMS analysis. European Journal of Endocrinology 2013168 297-305. (doi:10.1530/EJE-12-0807)

59 Child CJ, Zimmermann AG, Scott RS, Cutler GB Jr, Battelino T, Blum WF \& GeNeSIS International Advisory Board. Prevalence and incidence of diabetes mellitus in GH-treated children and adolescents: analysis from the GeNeSIS observational research program. Journal of Clinical Endocrinology \& Metabolism 201196 E1025-E1034. (doi:10.1210/jc.2010-3023)

60 Cutfield WS, Wilton P, Bennmarker H, Albertsson-Wikland K, Chatelain P, Ranke MB \& Price DA. Incidence of diabetes mellitus and impaired glucose tolerance in children and adolescents receiving growth-hormone treatment. Lancet 2000355 610-613. (doi:10.1016/ S0140-6736(99)04055-6)

61 Lagrou K, Xhrouet-Heinrichs D, Massa G, Vandeweghe M, Bourguignon JP, De Schepper J, de Zegher F, Ernould C, Heinrichs C, Malvaux $\mathrm{P}$, et al. Quality of life and retrospective perception of the effect of growth hormone treatment in adult patients with childhood growth hormone deficiency. Journal of Pediatric Endocrinology \& Metabolism 200114 1249-1260.

62 Stabler B. Impact of growth hormone (GH) therapy on quality of life along the lifespan of GH-treated patients. Hormone Research 200156 55-58. (doi:10.1159/000048136)

63 Wiren L, Johannsson G \& Bengtsson BA. A prospective investigation of quality of life and psychological well-being after the discontinuation of GH treatment in adolescent patients who had GH deficiency during childhood. Journal of Clinical Endocrinology \& Metabolism 200186 3494-3498. (doi:10.1210/jc.86.8.3494)

64 van Nieuwpoort IC \& Drent ML. Cognition in the adult with childhoodonset GH deficiency. European Journal of Endocrinology 2008159 S53-S57. (doi:10.1530/eje-08-0279)

65 Attanasio AF, Shavrikova EP, Blum WF \& Shalet SM. Quality of life in childhood onset growth hormone-deficient patients in the transition phase from childhood to adulthood. Journal of Clinical Endocrinology \& Metabolism 200590 4525-4529. (doi:10.1210/jc.2005-0439)

Received in final form 18 April 2016

Accepted 28 April 2016 http://www.endocrineconnections.org

DOI: 10.1530/EC-16-0024 (c) 2016 The authors Published by Bioscientifica Ltd
This work is licensed under a Creative Commons Attribution-NonCommercial 4.0 International License. 